\title{
FINE NEEDLE ASPIRATION OF SALIVARY GLAND LESIONS- DIAGNOSTIC PITFALLS
}

\author{
Sushma H. M1, Shashidhar M. R², Meghashree V3, Muktha R. Pai ${ }^{4}$
}

${ }^{1}$ Assistant Professor, Department of Pathology, A. J. Institute of Medical Sciences, Mangalore.

${ }^{2}$ Assistant Professor, Department of Pathology, Yenepoya Medical College, Mangalore.

${ }^{3}$ Postgraduate Student, Department of Pathology, A. J. Institute of Medical Sciences, Mangalore.

${ }^{4}$ Professor, Department of Pathology, A. J. Institute of Medical Sciences, Mangalore.

\section{ABSTRACT}

\section{BACKGROUND}

The use of Fine Needle Aspiration Cytology (FNAC) in the diagnosis of salivary gland lesions has seen a significant rise. In majority of cases, FNAC is helpful in differentiating between benign and malignant lesions. However, many a times it becomes quite challenging to give a precise diagnosis. The sensitivity of diagnosis of malignant lesions is high, though specificity is low.

Aims-Objectives-1. To study the cytomorphology of salivary gland lesions. 2. To examine the sensitivity, specificity and diagnostic accuracy of FNAC of salivary gland lesions by cytohistopathological correlation and to identify the discrepancies that contribute to false diagnosis.

\section{MATERIALS AND METHODS}

Fifty one salivary gland FNAC cases received at the Department of Pathology, A. J. Institute of Medical Sciences were reviewed to identify the cytological characteristics. A cytohistopathological correlation was done wherever available and discordant cases were analysed.

\section{RESULTS}

In the present study, out of 51 cases majority were males (33 cases, 65\%). Twenty (40\%) were diagnosed non-neoplastic, eighteen $(35 \%)$ were rendered benign, while thirteen $(25 \%)$ were malignant on cytology. Pleomorphic adenoma was the most common benign tumour (77\% of the benign lesions) and mucoepidermoid carcinoma was the most common malignant tumour (30\% of the malignant lesions). Biopsy confirmation of the cytological diagnoses were available in twenty one (41\%) cases; $42.8 \%$ of the total cases showed discordant diagnosis.

\section{CONCLUSION}

FNAC is a reliable tool in distinguishing benign and malignant salivary gland lesions in the hands of an experienced cytopathologist. A specific cytological diagnosis is often possible. However, due to the diagnostic pitfalls in FNAC, a biopsy confirmation may be necessary.

\section{KEYWORDS}

Correlation, Cytology, Histopathology, Pitfalls, Salivary Gland.

HOW TO CITE THIS ARTICLE: Sushma HM, Shashidhar MR, Meghashree V, et al. Fine needle aspiration of salivary gland lesionsdiagnostic pitfalls. J. Evolution Med. Dent. Sci. 2017;6(8):600-604, DOI: 10.14260/Jemds/2017/128

\section{BACKGROUND}

The use of Fine Needle Aspiration Cytology (FNAC) in the diagnosis of salivary gland lesions has seen a significant rise. FNAC is helpful in differentiating benign and malignant lesions in majority of the cases. However, many a times arriving at a precise diagnosis comes across as quite a challenge, because of the diverse morphological patterns and overlapping features between benign and malignant lesions.

Interpretation of FNAC of salivary glands has many problems and pitfalls. Some of these are due to the varied and heterogeneous nature of salivary gland neoplasia.

Others may be due to uncertainty as to the site and tissues aspirated, minimal material and lack of architectural pattern in the smears compared to histological sections.

Financial or Other, Competing Interest: None.

Submission 09-01-2017, Peer Review 21-01-2017,

Acceptance 23-01-2017, Published 25-01-2017.

Corresponding Author:

Dr. Shashidhar M. R,

Assistant Professor,

Department of Pathology,

Yenepoya Medical College,

Deralakatte, Mangalore-575018.

E-mail: shash.mr@gmail.com

DOI: $10.14260 /$ jemds $/ 2017 / 128$

\section{Aims/Objectives}

1. To study the cytomorphology of salivary gland lesions.

2. To examine the sensitivity, specificity and diagnostic accuracy of FNAC of salivary gland lesions by cytohistopathological correlation and to identify discrepancies that contribute to false diagnosis.

\section{MATERIALS AND METHODS}

The present study was carried out in the Department of Pathology, A. J. Institute of Medical Sciences and Research Centre, Mangalore. Fifty one salivary gland FNAC cases were reviewed to identify the cytological characteristics. FNAC was performed from different sites of the salivary gland swelling using a $10 \mathrm{~mL}$ disposable syringe and 23/24 gauge needle without local anaesthesia. FNAC air dried smears were stained with May-Grunwald-Giemsa stain and wet smears fixed in 95\% ethyl alcohol were stained with Papanicolaou stain. Corresponding paraffin embedded tissue sections obtained from salivary gland tissue were stained with haematoxylin and eosin whenever available. Salivary gland lesions were studied and classified cytologically under three groups: non-neoplastic lesions, benign and malignant tumours. A cytohistopathological correlation was carried out wherever available and the discordant cases were identified. 


\section{RESULTS}

The study group consisted of thirty three males (65\%) and eighteen females. Out of a total of fifty one cases, twenty (40\%) were diagnosed as non-neoplastic lesions, eighteen (35\%) were benign, while thirteen (25\%) were rendered malignant on cytology. Pleomorphic adenoma was the most common benign tumour and mucoepidermoid carcinoma was the most common malignant tumour. Biopsy confirmation of the diagnoses were available in twenty one cases (41\%).

Out of twenty non-neoplastic lesions histopathology was available only in four cases $(20 \%)$, of which the absence of neoplasm was confirmed in two cases. Discordance in typing was present in one case. Another case was that of chronic sialadenitis on FNAC, which turned out to be adenoid cystic carcinoma on histopathology (Fig. 1).

Cytohistopathological correlation was available in twelve out of eighteen cases of benign tumours (75\%), seven (58\%) of which showed positive correlation. One interesting case was that where the smears showed epithelial cells arranged in cohesive clusters and scattered singly admixed in minimal stromal matrix with few hyaline globules and basement membrane material. Intranuclear inclusions were seen in a few epithelial cells. (Fig 2a) Owing to the scant stromal matrix, a differential diagnosis of adenoid cystic carcinoma was considered along with a cytological diagnosis of pleomorphic adenoma. Biopsy confirmation revealed cellular pleomorphic adenoma. (Fig. 2b) Another case for which a differential diagnosis of pleomorphic adenoma/myoepithelioma was given turned out to be myoepithelial carcinoma on histopathology (Table 1).

In case of malignant lesions, six out of thirteen cases (46\%) had followup biopsies available. Two cases (16\%) showed positive correlation, one a case of adenoid cystic carcinoma and the other a case of mucoepidermoid carcinoma. One case which was falsely diagnosed as acinic cell carcinoma on cytology turned out to be sebaceous carcinoma on biopsy (Fig. 4).

With respect to specific typing of the lesion, six cases showed discordant diagnosis. (Table 1) Summary of the discordant cases: The first case was that of Sialadenoma papilliferum with chronic sialadenitis, which was incorrectly diagnosed as Warthin's tumour with squamous metaplasia cytologically. (Fig. 3) The second case was that of adenoid cystic carcinoma, which was misdiagnosed as papillary adenocarcinoma. The third case was that of clear cell renal cell carcinoma metastasis to the parotid, which was misinterpreted as poorly differentiated acinic cell carcinoma on FNAC. The fourth case was that of lymphoepithelial cyst which was incorrectly diagnosed as retention cyst. FNAC showed scant cellularity showing normal acini and ductal cells with a background of few lymphoid cells and foamy macrophages. Another case which was diagnosed as pleomorphic adenoma cytologically turned out to be Warthin's tumour. Yet another case which was diagnosed as Non-Hodgkin's lymphoma was given a diagnosis of undifferentiated salivary gland carcinoma on histopathology.

\begin{tabular}{|c|c|c|c|c|}
\hline No. & Site & FNAC Diagnosis & Histopathological Diagnosis & \\
\hline 1 & Palate & Chronic sialadenitis & Adenoid cystic carcinoma & FN \\
\hline 2 & Hard palate & Pleomorphic adenoma/Myoepithelioma & Myoepithelial carcinoma & FN \\
\hline 3 & Below left ear & Acinic cell carcinoma & Sebaceous carcinoma & $\mathrm{FP}$ \\
\hline 4 & Parotid cyst & $\begin{array}{l}\text { Warthin's tumour with squamous } \\
\text { metaplasia }\end{array}$ & $\begin{array}{l}\text { Sialadenoma papilliferum with chronic } \\
\text { sialadenitis }\end{array}$ & $\begin{array}{c}\mathrm{TP} \\
\text { discordance in } \\
\text { typing }\end{array}$ \\
\hline 5 & Submandibular & Papillary adenocarcinoma & Adenoid cystic carcinoma & \multirow{2}{*}{$\begin{array}{c}\text { TP, discordance in } \\
\text { typing }\end{array}$} \\
\hline 6 & Parotid & Poorly differentiated acinic cell carcinoma & Metastatic clear cell renal cell carcinoma & \\
\hline 7 & Parotid & Retention cyst & Lymphoepithelial cyst & $\begin{array}{c}\mathrm{TN}, \\
\text { discordance in } \\
\text { typing }\end{array}$ \\
\hline 8 & Parotid & Pleomorphic adenoma & Warthin's tumour & $\begin{array}{l}\text { TP, discordance } \\
\text { in typing }\end{array}$ \\
\hline 9 & Parotid & Non-Hodgkin's lymphoma & Undifferentiated salivary gland carcinoma & $\begin{array}{l}\mathrm{TP}, \text { discordance } \\
\text { in typing }\end{array}$ \\
\hline \multicolumn{5}{|c|}{ TP- True Positive, TN- True Negative, FP- False Positive, FN- False Negative } \\
\hline \multicolumn{5}{|c|}{ Table 1. Cytohistopathological Correlation of the Discordant Cases } \\
\hline
\end{tabular}

The sensitivity, specificity and diagnostic accuracy were $88.23 \%, 75 \%$ and $85.71 \%$ respectively. 

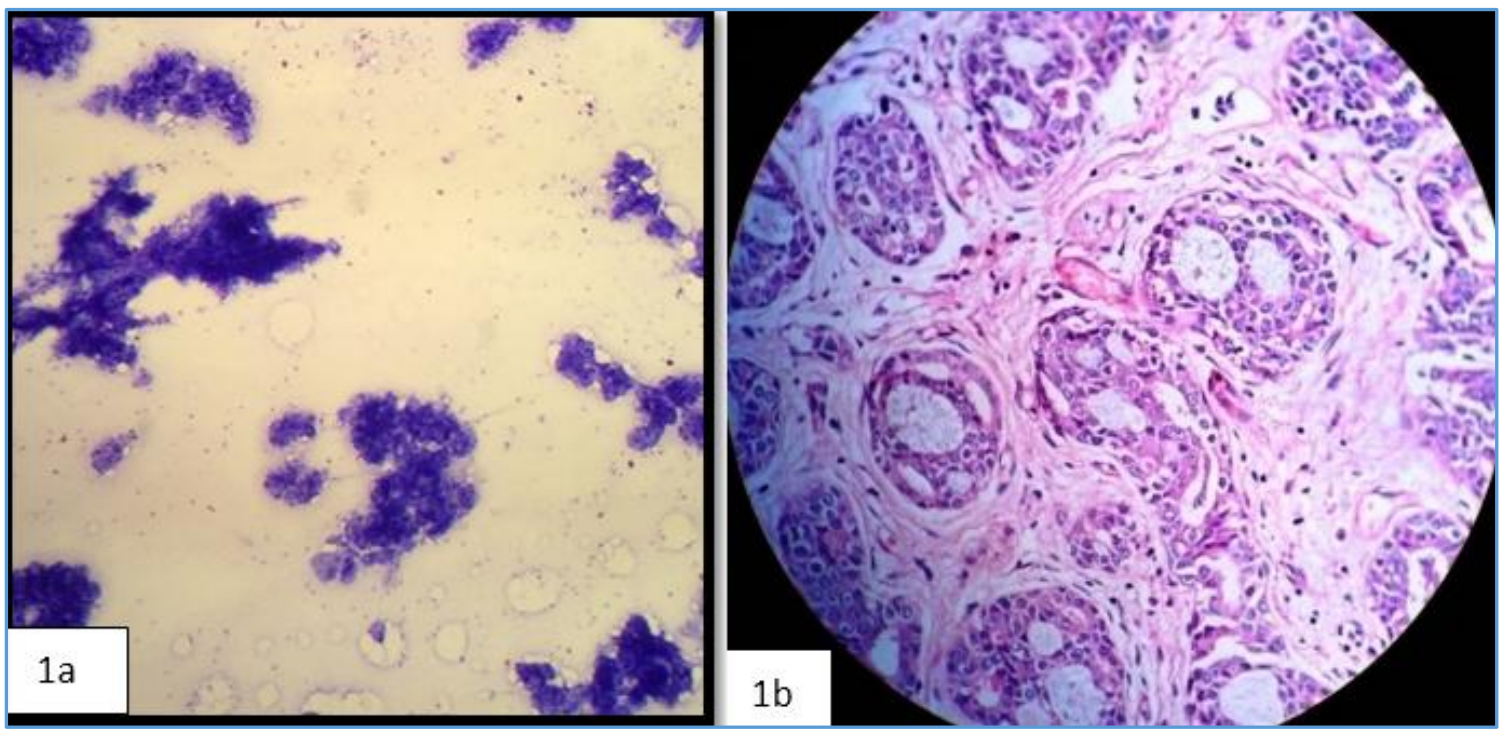

Figure 1. FNAC: Chronic Sialadenitis (1a) with corresponding Histopathology: Adenoid Cystic Carcinoma (1b)

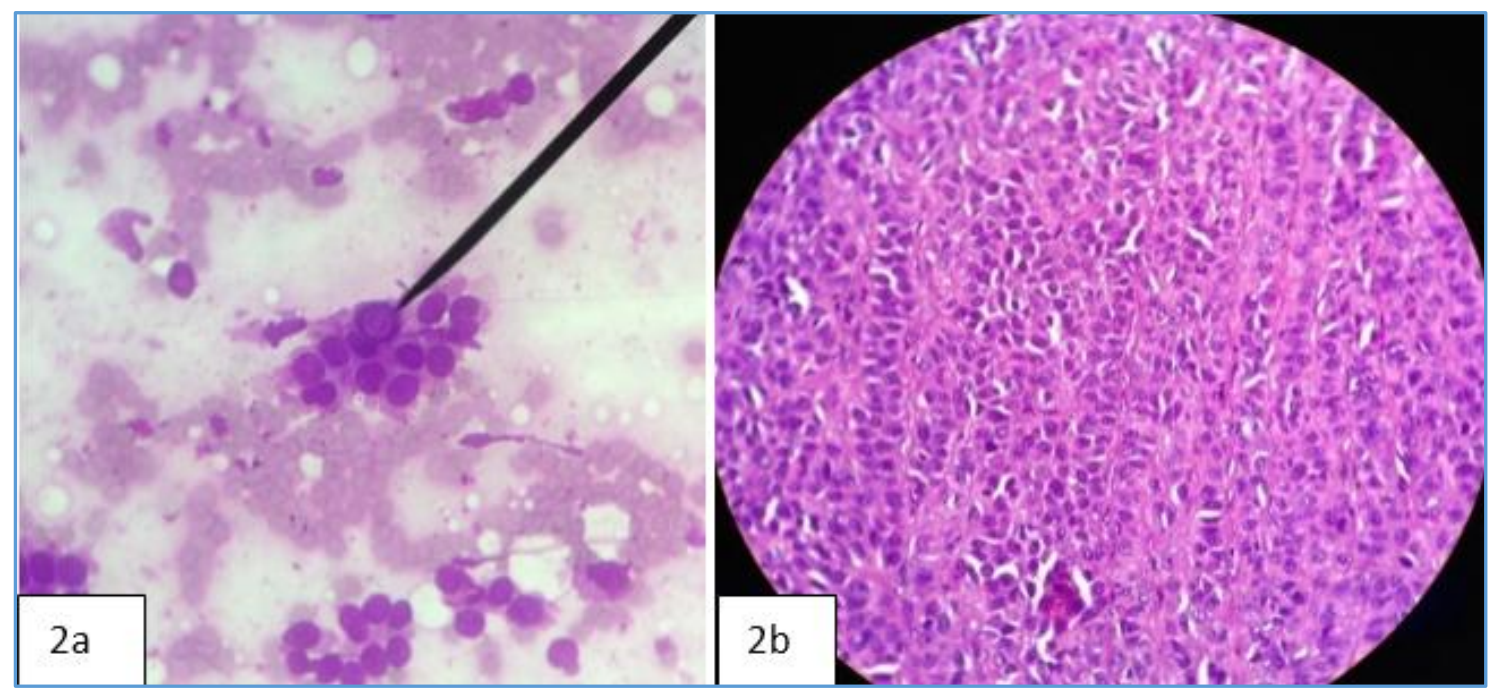

Figure 2. FNAC: Pleomorphic Adenoma with Intranuclear inclusion (2a) with corresponding Histopathology: Cellular Pleomorphic Adenoma (2b)

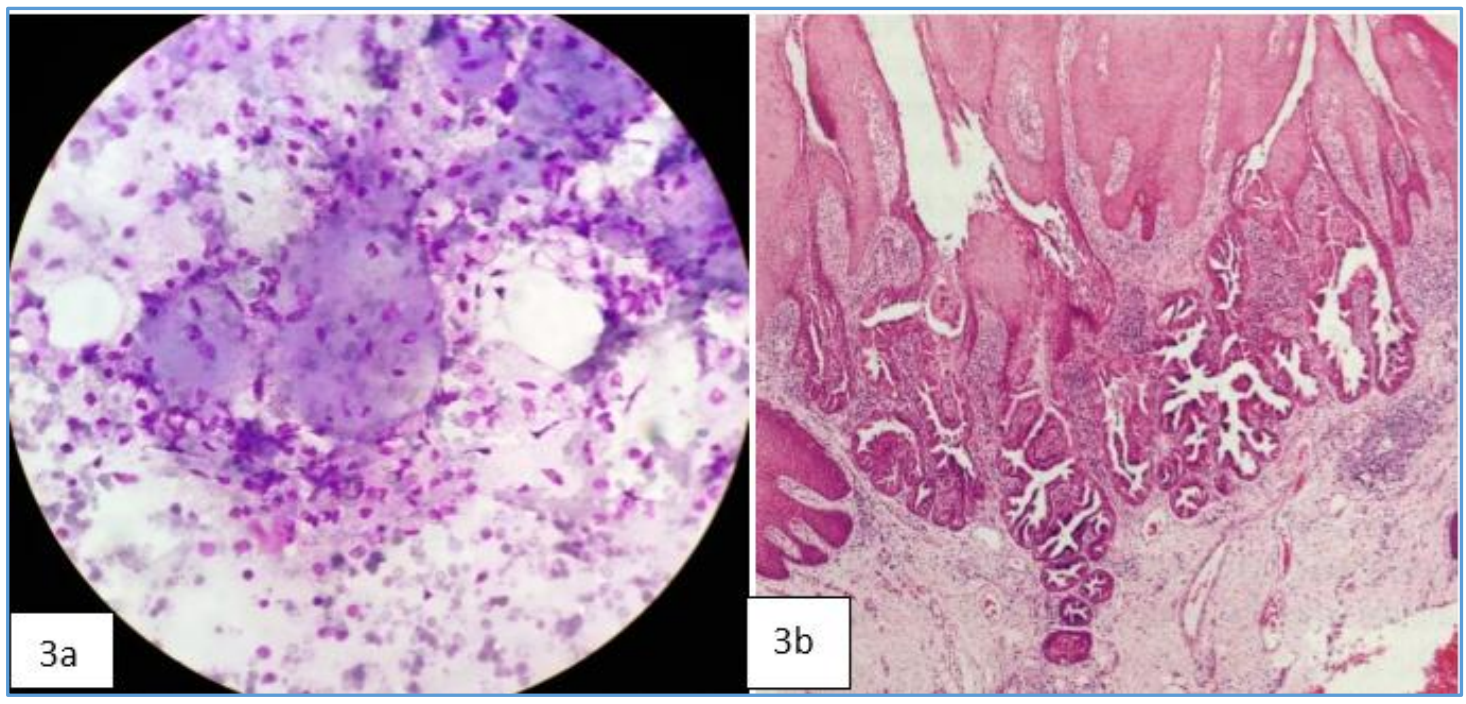

Figure 3. FNAC: Warthin's Tumour with Squamous Metaplasia showing Monolayered Sheets of Squamoid Cells, Angulated Cell Borders and Background of Lymphocytes (3a). Corresponding Histopathology: Sialadenoma Papilliferum (3b) 

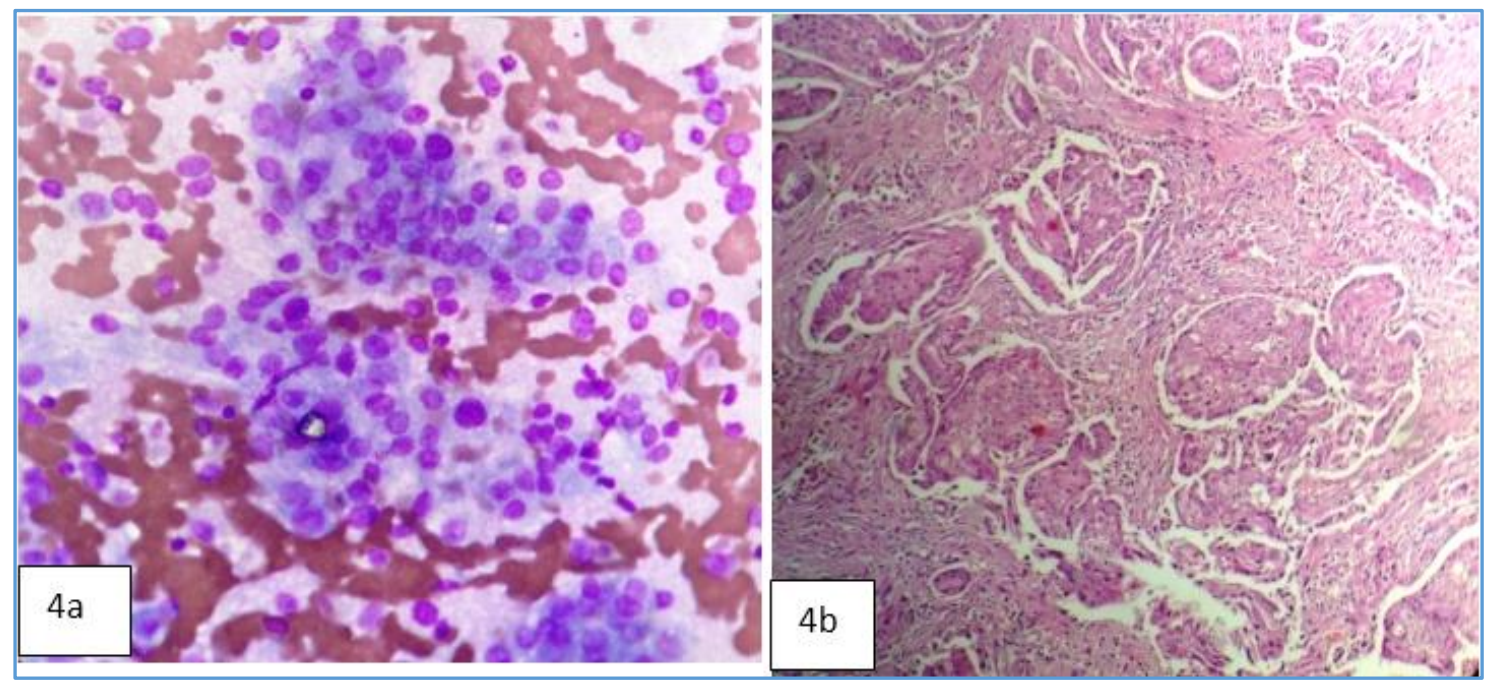

Figure 4. FNAC: Acinic Cell Carcinoma showing Uniform Cohesive Sheets with Vacuolated Cytoplasm (4a). Corresponding Histopathology: Sebaceous Carcinoma showing Lobules of Cells with Abundant Vacuolated Cytoplasm and centrally located Nuclei with Prominent Nucleoli (4b)

\section{DISCUSSION}

Salivary gland tumours account for about $3 \%-5 \%$ of all head and neck neoplasms in adults. FNAC is a quick, safe and relatively non-traumatic diagnostic procedure that can provide vital information preoperatively. ${ }^{1}$ The major role of FNAC is to assess whether a mass is non-neoplastic, benign or malignant and if possible render a specific diagnosis. ${ }^{2}$

FNAC interpretation of salivary gland lesions is extremely challenging due to a significant overlap in the morphologic patterns in many benign and malignant neoplasms and the heterogeneity in histologic pattern within the same tumour. ${ }^{3}$ Cytological features of majority of the salivary gland lesions have been described that are highly characteristic and reproducible. In majority of the cases the common variants of non-neoplastic and both benign and malignant neoplasms can be accurately diagnosed. However, for a proportion of problematic cases the cytologic criteria have not yet been established. 4,5 In such cases it would be wise to give a few differential diagnoses rather than issuing a misleading report that will lead to inappropriate surgery. ${ }^{3}$

The male-to-female ratio in the present study was 1.8:1. This was comparable to majority of other studies, which also showed a male predominance. In this study, benign and malignant tumours accounted for 35\% and 25\% respectively and majority of the benign tumours were pleomorphic adenoma (77\%), which was similar to those previously reported where pleomorphic adenoma accounted for nearly half of benign tumours. ${ }^{6}$

In our study sensitivity, specificity and diagnostic accuracy of FNAC were $88.8 \%, 66.6 \%$ and $83.8 \%$ respectively. In a study by Tohoun and Ezzat, 7 the sensitivity, specificity and diagnostic accuracy were $91.7 \%, 92.5 \%$ and $92 \%$ respectively. The sensitivity of our study was within the range of that reported in literature of $62 \%$ to $98 \%$. But specificity was lower (75\%) when compared to that mentioned in literature, i.e. $85 \%$ to $100 \% .^{8}$ The diagnostic accuracy of the present study (85.71\%) was comparable to other studies, i.e. $86 \%$ to $98 \% .{ }^{9}$ (Table 2 ).

\begin{tabular}{|c|c|c|c|}
\hline & $\begin{array}{c}\text { Present } \\
\text { Study (\%) }\end{array}$ & $\begin{array}{c}\text { Tohoun and } \\
\text { Ezzat (\%) }\end{array}$ & $\begin{array}{c}\text { Literature } \\
\text { (\%) }\end{array}$ \\
\hline Sensitivity & 88.23 & 91.7 & $62-98$ \\
\hline Specificity & 75 & 92.5 & $85-100$ \\
\hline $\begin{array}{c}\text { Diagnostic } \\
\text { Accuracy }\end{array}$ & 85.71 & 92 & $86-98$ \\
\hline \multicolumn{4}{|c|}{ Table 2. Comparison of Sensitivity, Specificity and } \\
Diagnostic Accuracy \\
\hline
\end{tabular}

The present study had two false negative cases, wherein adenoid cystic carcinoma was rendered as non-neoplastic on FNAC and a diagnosis of chronic sialadenitis was given. The FNAC smears showed sheets of ductal epithelial cells, few acinar cells and mild chronic inflammatory cell infiltrate in a background of mucoid material and blood. (Fig 1a) The cytological picture of chronic sialadenitis depends on when in the course of the disease, the aspirate is obtained. Adenoid cystic carcinoma can be difficult to diagnose because of the relatively small size of the tumour nuclei, good cell to cell cohesion and rather bland appearance, leading to a wrong diagnosis. The error could be also due to inadequate aspirate and this highlights the importance of multiple sampling. Second was a case with a differential diagnosis of pleomorphic adenoma and myoepithelioma, which turned out to be myoepithelial carcinoma. Myoepithelial carcinoma, the malignant counterpart of benign mesothelioma is one of the rarest salivary gland neoplasms. Reticular variant of myoepithelial carcinoma may be mistaken for a variety of benign and malignant epithelial and mesenchymal tumours including mixed tumour (Pleomorphic adenoma), adenoid cystic carcinoma, basal cell adenoma and epithelial myoepithelial carcinoma. Awareness of this variant is emphasised to prevent misdiagnosis. ${ }^{10}$

One case which was diagnosed as poorly differentiated acinic cell carcinoma of parotid gland on FNAC turned out to be metastatic clear cell renal cell carcinoma on histopathology. Acinic cell carcinoma can occur in both major and minor salivary glands. FNAC will yield clusters and aggregates of cells bearing striking resemblance to normal acinar cells, especially in the usual well-differentiated type. Renal cell carcinoma can metastasise to the parotid gland and 
must be remembered in the differential diagnosis. The characteristic vascular pattern of clear cell renal cell carcinoma is a clue and nuclear atypia is usually more prominent. ${ }^{11}$ The accurate diagnosis of these neoplasms depends on clinical presentation, age of onset and clinical history. In this case, no clinical history was given and no prior investigations were performed which pointed towards a primary renal carcinoma. In the absence of any clinical history/suspicion, a diagnosis of poorly differentiated acinic cell carcinoma was made purely based on morphology.

Similarly, sebaceous carcinoma was misinterpreted as acinic cell carcinoma cytologically leading to a false positive diagnosis owing to the overlap in the cytological picture namely relatively uniform cohesive cells with abundant vacuolated cytoplasm and nuclei with bland chromatin. (Fig. 4) Moreover the location of the tumour, i.e. below the ear was also a misleading factor.

A case of sialadenoma papilliferum with chronic sialadenitis was rendered a benign diagnosis on FNAC. However, there was discordance in typing and a diagnosis of Warthin's tumour with squamous metaplasia was given. The presence of benign squamoid cells with lymphocytes and oncocytic cells in FNAC of parotid cyst gave a presumptive diagnosis of Warthin's tumour (Fig. 3a).

A case of adenoid cystic carcinoma was misdiagnosed as papillary adenocarcinoma cytologically, because the hyaline material was minimal and the cribriform and tubular patterns were not seen on FNAC.

Another discordant diagnosis with respect to typing was a case of lymphoepithelial cyst, misdiagnosed as retention cyst. Lymphoepithelial cysts are more commonly seen in HIVinfected patients and smears show lymphoid cells from subepithelial lymphoid tissue, 11 which may be absent in late stages of the disease. In the present case owing to the scant cellularity, the diagnosis may have been given as retention cyst. Histopathology showed only one focus of lymphoid aggregate. Thus, inadequate material/sampling might have led to the misinterpretation.

A case of Warthin's tumour was misinterpreted as pleomorphic adenoma cytologically. This may be due to presence of metaplastic (oncocytic) changes in pleomorphic adenoma. ${ }^{11}$

Some NHLs (Diffuse large B cell lymphoma) of salivary gland cytologically mimic undifferentiated carcinoma, which might have led to a misdiagnosis of the same. ${ }^{12}$

\section{CONCLUSION}

FNAC is a reliable tool in distinguishing benign and malignant salivary gland lesions in the hands of an experienced cytopathologist. Proper sampling of lesions and adequate cellularity of smears are pre-requisites for an accurate diagnosis. Pitfalls in cytological diagnosis were due to errors in sampling and interpretation of smears and lack of clinical history. The comparative study will be better if the sample size is larger. FNAC diagnosis of salivary gland lesions can be fraught with problems and pitfalls due to which a biopsy confirmation may be necessary.

\section{REFERENCES}

[1] Frable WJ. Thin needle aspiration biopsy. Philadelphia: WB Saunders 1983:119-51.

[2] Shiantani S, Matsura H, Hasegawa Y. Fine needle aspiration of salivary gland tumours. Int J Oral MaxilloFac Surg 1997;26:284-6.

[3] Schindler S, Nayar R, Dutra J, et al. Diagnostic challenges in aspiration cytology of the salivary glands. Semin Diagn Pathol 2001;18(2):124-46.

[4] Orell SR. Diagnostic difficulty in the interpretation of FNA of salivary lesions: the problem revisited. Cytopathol 1995;6(5):285-300.

[5] Lowhagen T, Tani EM, Skoog L. Salivary glands and rare head and neck lesions. In: Bibbo M. edr. Comprehensive cytopathology. Philadelphia: WB Saunders 1991:62148.

[6] O'Dwyer P, Farrar WB, Jame AG, et al. Needle aspiration biopsy of major salivary gland tumours: its value. Cancer 1986;57(3):554-7.

[7] Tahoun N, Ezzat N. Diagnnostic accuracy and pitfalls of preoperative fine needle aspiration cytology in salivary gland lesions. Journal of the Egyptian Nat Cancer Inst 2008;20(4):358-68.

[8] Koss LG, Melamed MR. Salivary Glands. In: Diagnostic cytology and its histopathologic bases. $5^{\text {th }}$ edn. Philadelphia: Lippincott Williams and Wilkins 2006; 1230-60.

[9] Rajwanshi A, Gupta K, Gupta N, et al. Fine needle aspiration cytology of salivary glands: diagnostic pitfalls-revisited. Diagnostic Cytopathol 2006;34(8):580-4.

[10] Azizun-Nisa, Kazi JI, Jamal S. Reticular type parotid myoepithelial carcinoma: an intriguing variant and mimicker. J Coll Physicians Surg Pak 2013;23(5):353-5.

[11] Orell SR, Klijanienko J. Head and neck: salivary glands. Fine needle aspiration cytology. $5^{\text {th }}$ edn. Churchill Livingstone: 2012.

[12] Cibas ES, Ducatman BS. Salivary gland. Diagnostic principles and clinical correlates. $3^{\text {rd }}$ edn. Philadelphia, PA: Saunders Elsevier 2009. 